\title{
Diffuse Large B-Cell Lymphoma of the Central Nervous System. Immunophenotype, Clinicopathological Features and Differential Diagnosis
}

\author{
Mónica Belinda Romero-Guadarrama ${ }^{{ }^{*}}$, María Esther Gutiérrez Díaz-Ceballos ${ }^{1}$, \\ Fiacro Jiménez-Ponce ${ }^{2}$, Samantha Thingen-Velarde ${ }^{3}$ \\ ${ }^{1}$ Unit Pathology Hospital General de México, Medicine School, Autonomous University of Mexico, Mexico City, Mexico; ${ }^{2}$ Neurosur- \\ gery Unit Hospital General de México, Mexico City, Mexico; ${ }^{3}$ Hemathology Service, Hospital General de México, Mexico City, Mexico. \\ Email: *monicaromero@att.net.mx
}

Received June $14^{\text {th }}, 2012$; revised July $12^{\text {th }}, 2012$; accepted July $23^{\text {rd }}, 2012$

\begin{abstract}
Background: Diffuse large B-cell lymphomas of the central nervous system (DLBCL CNS) represent less than 1\% of all lymphomas and between $2 \%$ and $3 \%$ of all cerebral tumors. They occur in adults of 60 years of age or more. The objective of this work is to describe the clinical-pathological characteristics, the immunophenotype and the differential diagnosis. Clinical Case: From the files of the surgical pathology unit we found four cases of primary diffuse large B cell lymphoma of the central nervous system in a 6-year period. Three corresponded to women over 47 years of age and the other to a 42-year-old man. The time of evolution was between 2 and 4 months. The symptoms were headache, blurred vision, hemiparesis, and seizures. Localization was in the pineal region, the frontal, parietal regions, and the right thalamus. Morphologically, large lymphoid cells with a diffuse growth pattern and necrosis were observed. Immunohistochemical markers, such as CD 20 and bcl2 were positive, one was positive to CD3. Expression of bcl6 and CD 10 was positive in one case, and MUM-1 was positive in three cases. All the cases were negative for Epstein-Barr virus. Conclusions: The diffuse large-B cell lymphoma of the central nervous system is rare. Its average age of presentation is at 60 years or older. The localization is in the pineal, frontal, parietal and thalamic regions. Three cases were originated by activated B lymphocyte (MUM-1 expression) and other from the Germinal Center (GC) (CD 10 expression). The clinical course was bad. The four patients died shortly after the diagnosis.
\end{abstract}

Keywords: Primary Lymphoma; Central Nervous System

\section{Introduction}

Primary lymphomas of the central nervous system are immunophenotype $\mathrm{B}$ lymphomas with an aggressive clinical course and, in general, correspond to diffuse large B cell lymphomas and Burkitt’s lymphoma. Rare cases of small lymphocyte lymphomas have been reported [1].

The average age of presentation in non-immunocompromised patients is around 60 years, when occurring in patients with HIV syndrome the age of presentation is 5 to 10 years earlier. Symptoms depend on the anatomical location, although they are frequently located in the cerebral hemispheres, around $60 \%$ are found in the supratentorial area. [2] Symptoms are focal and/or are caused by the increase in intracranial pressure that can be rapidly progressing.

Radiological studies such as MRI (Magnetic Reso-

${ }^{*}$ Corresponding author. nance Image) or CAT (Computed Axial Tomography) scan of the brain reveal heterogeneous lesions with signs of central necrosis; in $20 \%$ to $40 \%$ of cases, multiple lesions can be observed. Diagnosis is histopathological and tissue can be obtained by either stereotactic biopsy or craniotomy.

Most of these lymphomas present cells that resemble blasts, with a diffuse infiltration pattern and frequently, cells are distributed around the blood vessels, with a concentric pattern accompanied by an increase in reticulin fibers. Most of these tumors can be classified as centroblastic.

They express markers for B cells, such as CD 20, CD 22 , or CD $79^{\mathrm{a}}$, and an important percentage (89\%) express MUM-1.

Prognosis is poor and differential diagnosis must be made from other tumors of the central nervous system.

The objective of this study is to present the clinicopathological, immunophenotype characteristics and the dif- 
ferential diagnosis of this rare type of lymphoma in non-immunocompromised patients.

\section{Clinical Cases}

In the surgical pathology archives of the Pathology Unit of the General Hospital of Mexico and of the School of Medicine (UNAM), in a 6-year period, we found four patients with a diagnosis of diffuse B lymphoma of large cells with primary presentation at the central nervous system.

In the clinical files we searched for symptomatology, radiological findings, clinical diagnoses, treatment and follow-up.

We reviewed the histological sections stained with hematoxylin-eosin, Shiff's periodic acid, and staining of the reticulum. Immunohistochemical reactions were made manually with the avidin-biotin-peroxidase technique with previous antigenic recovery, for this, we used citrate buffer at $99^{\circ} \mathrm{C}$ during $10 \mathrm{~min}$ in a pressure cooker.

Monoclonal antibodies used were CD 20 (L-26 clone Dako Cytomation), CD 3 (rabbit monoclonal antibodies; Dako Cytomation), CD 10 (clone 56C; Novocastra Laboratories), bcl2 (clone 124; Dako Cytomation), bcl6 (clone PGB6p; Dako Cytomation), MUM 1 protein (clone MUM1p; Dako Cytomation) and LMP-1 (clone Zebra/Dako Cytomation). Diaminobenzidine was used for microscopic evaluation.

From a total of 357 biopsies with diagnosis of diffuse large B-cells lymphoma originated in lymph node, palatine tonsil, digestive tract, and other sites in a 6-year period (2004-2010), we identified four patients whose primary site of origin was the central nervous system (1.1\%).

\section{Case Reports}

\subsection{Case 1}

Male, 42 years old, immunocompetent. He started with clinical symptoms 4 months before his death. Symptoms were loss of recent memory, parestesis of lower limbs, then holocranial cephalalgia, nausea, vomiting, blurred vision, and left hemiparesis were added (Table 1). Neuro- logical exploration revealed altered mediate and inmmediate memory. MRI revealed a heterogeneous lesion, of irregular borders, neoplastic aspect, in the pineal region as well as ventricular dilation (Figure 1). Therefore, he was subjected to partial resection of the tumor lesions through right parietal craniotomy.

The radiological diagnosis was of an astrocytoma in the pineal region. He evolved torpidly and died during the immediate postoperative period.

The surgical specimen consisted of several irregular fragments of tissue, brown-grayish, that measured as a whole $3 \times 2 \times 1.3 \mathrm{~cm}$.

Histology revealed a lymphoid neoplasm constituted by large cells, of inconspicuous cytoplasm, ovoid nuclei, discretely pleomorphic, and with nucleoli marginal to the nuclear membrane with a perivascular and concentric disposition (Figure 2), which became more evident with the staining of the reticulum. In Table 2 presents a sum-

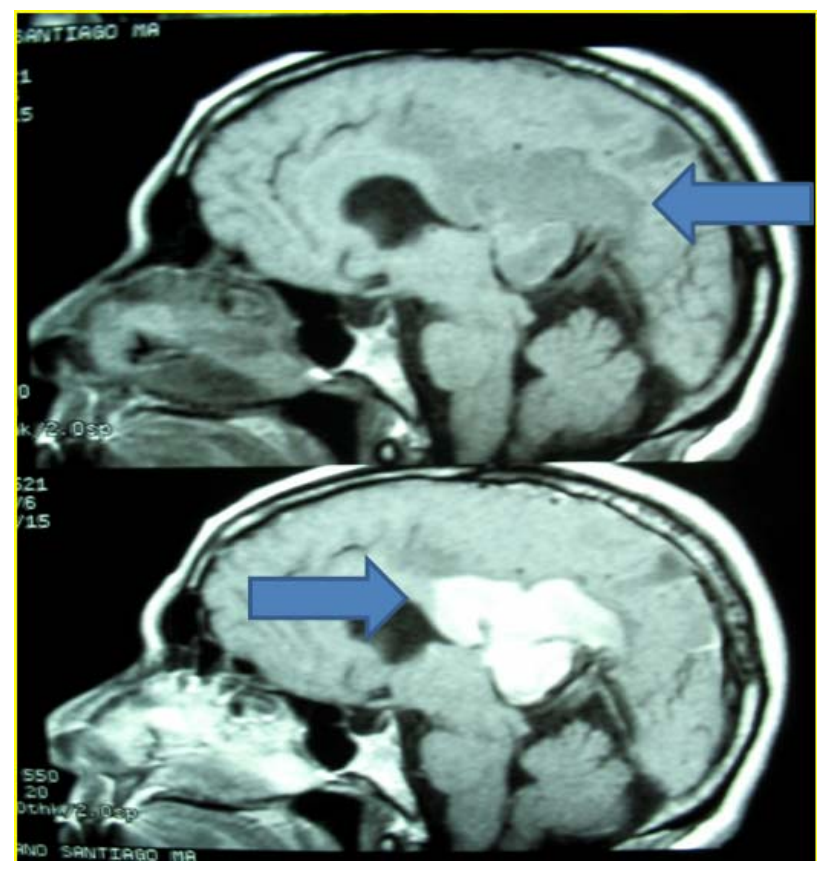

Figure 1. Case 1. MRI of the brain, revealing a heterogeneous lesion of irregular borders in the pineal gland region and ventricular dilation.

Table 1. Radiological characteristics and clinical diagnosis.

\begin{tabular}{|c|c|c|c|c|c|}
\hline Gender & Age & Site & Symptoms & Diagnosis & Type of lymphoma \\
\hline 1. $\mathrm{M}$ & 42 & Pineal & Memory alterations parestesis, blurred visión & Astrocytoma & DLBCL ABL \\
\hline 2. $\mathrm{F}$ & 67 & Parasagittal and frontal & Hemiparesis, seizures and cephalalgia & Meningioma & DLBCL ABL \\
\hline 3. $\mathrm{F}$ & 47 & Thalamus & $\begin{array}{l}\text { Hemiparesis, blurred visión, convulsive crisis } \\
\text { and cephalea }\end{array}$ & Glioma vs lymphoma & $\begin{array}{l}\text { DLBCL GC } \\
\text { Expression to CD } 3\end{array}$ \\
\hline 4. $\mathrm{M}$ & 85 & Temporal & Dysarthria, monoparesis, right fasciculations & Tumor of the Central Nervous System & DLBCL ABL \\
\hline
\end{tabular}

$\mathrm{M}=$ male; $\mathrm{F}$ = female; DLBCL = Diffuse large B-cell lymphoma. ABL Activated B lymphocyte DLBCL GC = Diffuse large B. cell lymphoma originated in the germinal center by immunophenotype. 
mary of the immunohistochemical reactions that expressed CD 20, bcl 2, and Mum-1. Bone marrow presented no alterations.

\subsection{Case 2}

Woman, 67 years, immunocompetent. She started the clinical symptoms two months before she died. Symptom were diminution of muscular strength in the left hemibody, that made deambulation impossible and right cephalalgia. Besides she coursed with partial seizures characterized by involuntary movements of the left thoracic member, as summarized in Table 1.

Physical exploration revealed psychomotor agitation, understandable speech, disoriented temporally and spatially. She presented left hemiparesis and hyperreflexia and Babinski. MRI (Magnetic Resonance Image) of the brain revealed hyperintense images in $\mathrm{T} 1$, in right parasagittal and frontal regions, with perilesional edema that caused diminution of the subarachnoid space toward convexity.

Based on the diagnosis of meningioma of the convexity, right fronto-parietal craniotomy and tumoral resection were performed. She died afterward.

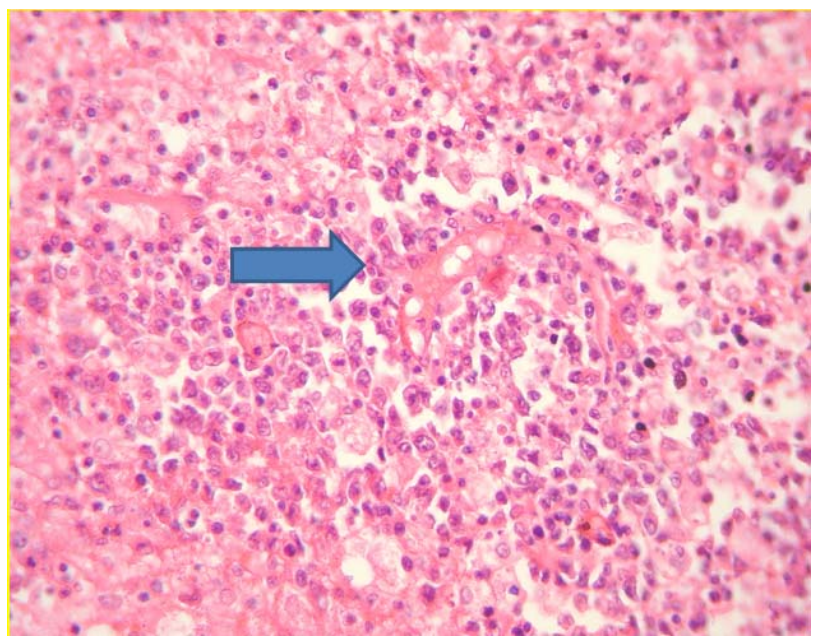

Figure 2. Case 1. Large lymphoid cells, nuclei with evident nucleoli and perivascular disposition can be identified morphologically (10× H-E).
Surgical specimen consisted of several fragments of soft-consistency, white-grayish tissue that showed areas of necrosis and as a whole measured $5 \times 3 \times 2 \mathrm{~cm}$.

Histology revealed a lymphoid neoplasm constituted by large cells with a more or less evident cytoplasm, irregular ovoid nuclei, marginal nucleoli, split nuclei with an evident single nucleoli; disposition of cells was diffuse and perivascular and became evident by staining the reticulum (Figure 3).

Immunohistochemical reaction such as CD20 and bcl2 were positive in the membrane of neoplastic cells and Mum-1 was positive in the nuclei of the neoplastic cells. CD3, CD10, bcl6 and LMP-1 were negative, as indicated in Table 2. Bone marrow without alterations.

\subsection{Case 3}

Woman, of 47 years of age, who presented blurred vision of the left eye, with 2 months of evolution; then, left hemiparesis, right fronto-parietal cephalea, and convulsive crisis were added. Physical exploration revealed visual hallucinations, papilledema, right facial hemiparesis. Laboratory tests revealed no alterations. MRI revealed a heterogeneous image at the level of the right thalamus measuring $3 \times 1.5 \mathrm{~cm}$.

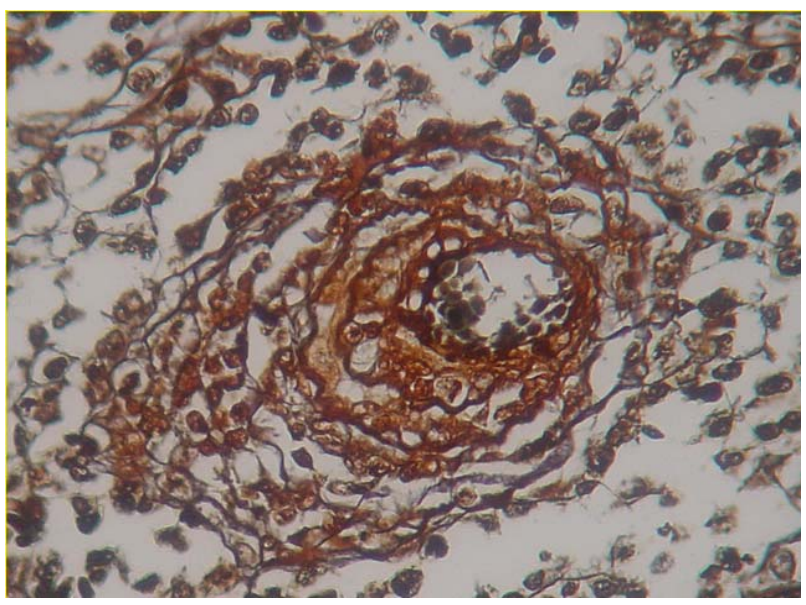

Figure 3. Case 2. Staining of the reticulum evidences the concentric disposition of the tumor cells $(10 \times$ reticulum staining).

Table 2. Morphology and immunophenotype characteristics of primary DLBCL of the CNS.

\begin{tabular}{ccc}
\hline No. of case & Morphology & Immunophenotype \\
\hline 1. & CB, necrosis, perivascular pattern & CD 20+, CD 3-, Mum-1+, CD 10-, bcl2+, bcl6-, LMP-1- \\
2. & CB, reactive gliosis, perivascular pattern & CD 20+, CD 3-, Mum-1+, CD 10-, bcl2+, bcl6-, LMP-1- \\
3. & CB, perivascular pattern & CD 20+, CD 3+, Mum-1-, CD 10+, bcl2+, bcl6+, LMP-1- \\
4. & CB, focal perivascular pattern & CD 20+, CD 3-, Mum-1+, CD 10-, bcl2+, bcl6- LMP-1- \\
\hline
\end{tabular}

CNS = Central Nervous System; DLBCL = Diffuse large B-cell lymphoma; CB = Centroblastic. LMP-1 (Latent membrane protein of the Epstein-Barr virus); $\mathrm{M}=$ male; $\mathrm{F}$ = female; DLBCL = Diffuse large B-cell lymphoma. ABL Activated B lymphocyte DLBCL. GC = Diffuse large B. cell lymphoma originated in the germinal center by immunophenotype. 
Clinical diagnosis was of glioma vs basal nuclei lymphoma, as indicated in Table 1. Cerebral biopsy was performed through stereotaxy.

Morphologically it was similar to the two previous cases, however many of the neoplastic cells expressed CD 20 and CD 3 (Figures 4 and 5), as well as germinal center markers (CD 10 and bcl6) as shown in Table 2. Biopsy or the bone marrow revealed myelofibrosis grade I, without infiltration.

The patient evolved well after high doses of intravenous methotrexate (10 doses of $25 \mathrm{mg}$ ) and rescue with folinic acid $24 \mathrm{~h}$ afterward. Clinical follow up was of 4 months, with persistence of cephalalgia and eventual death.

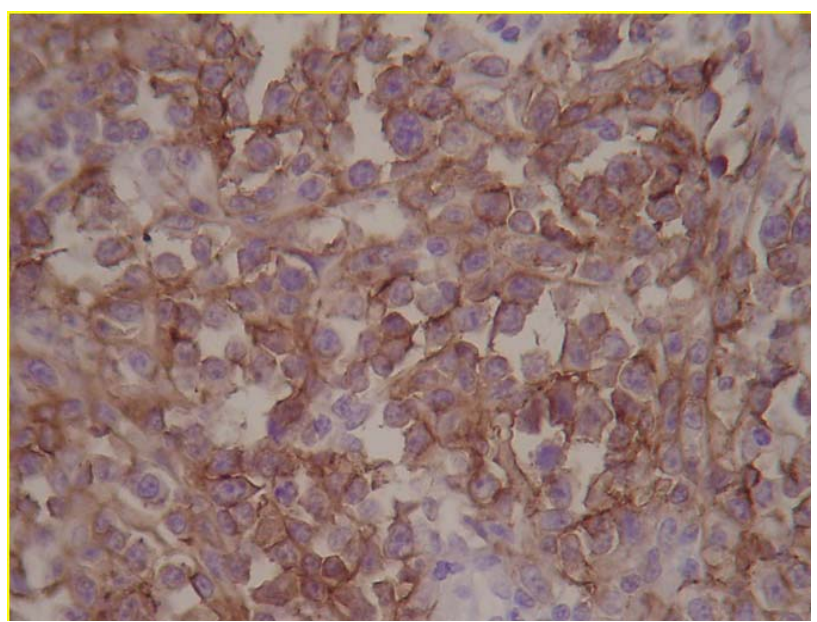

Figure 4. Case 3. Anti-CD 30 immunohistochemical reaction that is positive in the cytoplasmic membrane of the neoplastic cells (40× Inmunoperoxidase).

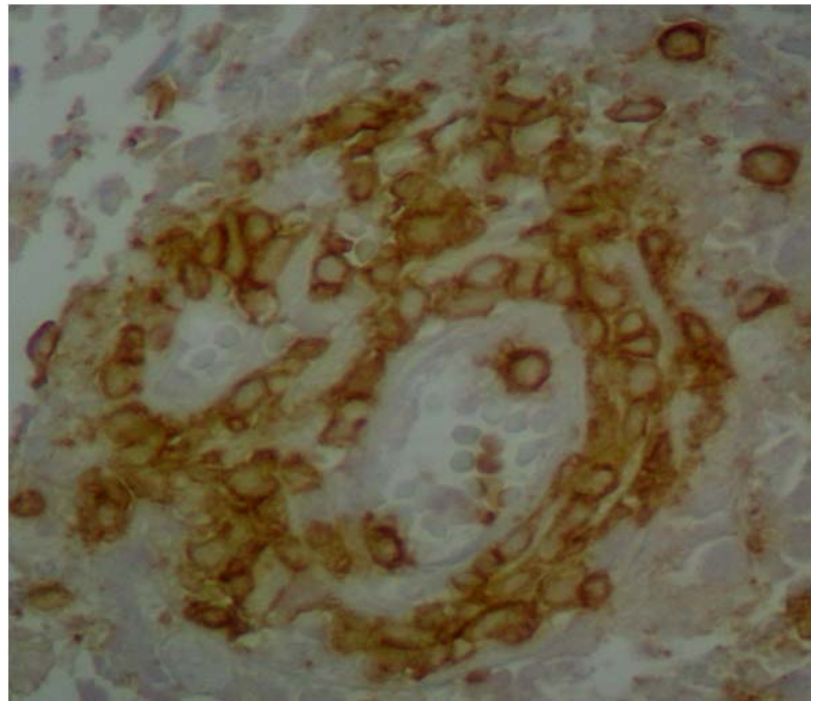

Figure 5. Case 3. Aberrant expression of CD 3 in neoplastic cells that are distributed around the blood vessels $(40 \times$ Inmunoperoxidase).

\subsection{Case 4}

Woman of 85 years, with antecedents of systemic arterial hypertension and chronic obstructive pulmonary disease. She started with clinical symptoms one month before diagnosis. Symptoms were dysarthria, right monoparesis and facial fasciculations of the same side. Simple CAT scan of the brain and MRI revealed left parietal tumor (Figure 6), craniotomy was performed based on a clinical-radiological diagnosis of tumor of the central nervous system, as indicated in Table 1. Partial resection of the tumor was performed through craniotomy.

Several irregular fragments of tissue measuring $4 \times 3 \times$ $2 \mathrm{~cm}$ were received. Histology revealed a lymphoid tumor constituted by large cells, scarce cytoplasm, and irregular nuclei perivascularly distributed. Immnohistochemical markers were positive for CD 20, bcl2, and MUM-1 (Table 2). Post-operative period with clinical evolution of three months and eventual death.

\section{Discussion}

Primary lymphomas of the central nervous system (PLCNS) are non-Hodgkin extranodal lymphomas that occur in the craniospinal axis and most are highly malignant type B neoplasms [1,2]. They present at this site probably due to the tropism of lymphoid cells [3]. The biological mechanism of selective tropism is still unknown, and the genesis of this lymphoma in the central

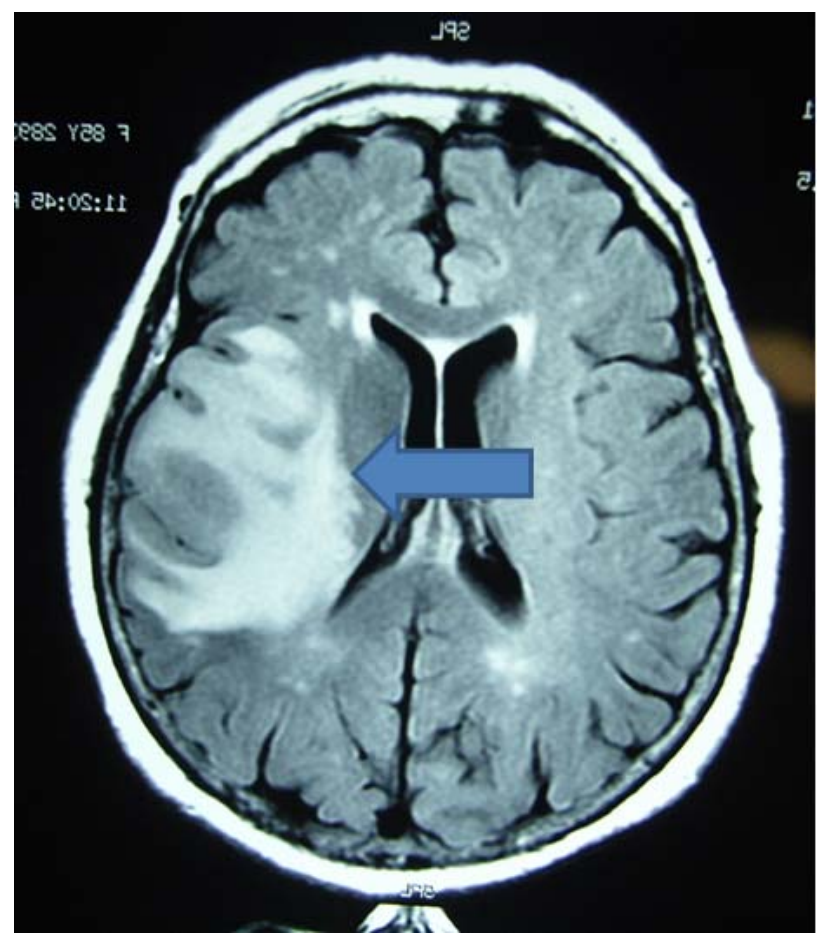

Figure 6. Case 4. MRI revealing a hyperintense homogeneous image, at the fronto-parietal level. 
nervous system is not completely understood; a probable hypothesis is that the tumor cells originate in extracranial sites [4].

The immunophenotype and the presence of rearranged, somatically mutated immunoglobulin (IG) genes with evidence for ongoing mutation suggest PCNSL tumor cells are derived from a germinal centre (GC) exit B cell [5]. Tumor manifestation is often diffuse, multifocal and frequently affects the supratentorial cerebral parenchyma. They occur in all age groups, with an incidence peak in the fifth or sixth decade of life in patients without AIDS [6]. In the present study, in a period of 6 years, four patients presented as primary site of the diffuse large B-cells lymphoma (DLBCL) the central nervous system, representing $1.1 \%$ of all the diffuse large cell lymphomas at diverse sites, including the lymph node, in our institution. Average age was of 60 years, being more frequent in women, which agrees with the corresponding literature of the American continent; other authors have found men to be more affected $[7,8]$.

Clinical sympthomatology curred 2 to 4 months before the diagnosis, hence the start is fast with just a few months before diagnosis. In the series by Bataille et al., the most common symptoms were neurological focality (70\%) and neuropsychiatric alterations (43\%); [9] in the present study, these were cephalea, hemiparesis, visual alterations and convulsive crises. The site most affected is the frontal lobe; in this series location was variable presenting in the pineal region, frontal lobe, parasagittal region, temporal lobe, and in the thalamic region, as summarized in Table 1. In more than half the cases, lesions are solitary (65\%), although multifocal lesions can be observed (35\%) [10,11]. The CAT scan reveals isodense and hyperintense lesions, and with MRI they appear isointense and hypointense and can present perilesional edema and mass effect. In our patients, these changes in MRI were heterogeneous, without a predominating pattern, lesions were localized in three, and one showed multifocal lesions. DLBCLs presenting in the CNS are generally intraparenchymatous and with periventricular affection, the latter is a very important piece of information for the differential diagnosis between primary and secondary lymphomas, since the latter affect mainly the leptomeninges [12]. Morphologically, neoplastic cells are large, barely evident cytoplasm and nuclei that resemble centroblasts, as can be seen in Figure 2, although they can exhibit an immunoblast morphology [1] with a diffuse growth pattern and perivascu lar disposition and concentric accentuation (Figure 3), tumor cells alternate with small reactive lymphocytes, macrophages, activated microglial cells, and reactive astrocytes [13].

They express pan-B markers such as CD 20 and CD $79^{\mathrm{a}}$ (Figure 4), they can express bcl2 and CD 10, not related to $t(14 ; 18)$ (q32; q21). Expression of bcl-6 has been associated with a favorable prognosis. However, strong expression of RF4/MUM-1 has been observed in approximately $90 \%$ of cases $[14,15]$.

Our results agree with previously reported data in other series. DLBCLs in the SNC frequently contain complex cytogenetic anomalies, diagnosis is based on the combination of histology, immunophenotype, and molecular clonality [16].

The aberrant expression of B-cell-associated antigens has been identified in benign proliferations of $\mathrm{T}$ cells and non-Hodgkin lymphomas with the immunophenotype $\mathrm{T}$ $[17,18]$. It is not rare that low-grade non-Hodgkin lymphomas co-express T-cell-associated antigens, particularly CD 5 and CD 43 [19,20]. There are T markers, such as CD 5, that are expressed in DLBCL without any other specification in lymph node and in other variants like large cell intravascular lymphomas [21,22] Cases of B lymphomas with aberrant co-expression to $\mathrm{T}$ cell-associated antigens, such as CD2, CD 4, CD 7, CD 8, and CD 45 RO have been reported [23-25]. In a recent study, Wang et al. [26] found four cases of DLBCL with aberrant expression to $\mathrm{CD} 3$, in one of the cases, the lymphoma occurred in the CNS in a 52-year-old woman; in the present study, expression of CD 3 was observed in a 47-year-old woman (Case 3) (Figure 5); the biological significance and the mechanism for the CD 3 expression in DLBCL is not known; hence, we believe that other pan B markers such as CD 79a, CD 138, PAX 5, and Mum-1 must be determined or molecular biology techniques must be implemented for the correct determination of the cell lineage of these unusual lymphomas. In the present series, three DLBCL in the SNC expressed Mum-1 and all expressed bcl-2 markers of bad prognosis; in a recent publication of 17 cases, expression of bcl2 and STAT-3 (Signal transducer and activator of transduction) was studied, emphasizing the low expression of this marker as a subtype of diffuse large B cell lymphoma originated from activated lymphocytes [27].

Among the most significantly up-regulated genes in PCNSL were SPPI, TF, DDR1, TUBB2B, SERPINA3, S100B, and CA2. More than 460 expressed sequence tags were differentially expressed between PCNSL [27]. Regarding prognosis, several variables have been identified that affect survival negatively such as: age over 60 years, high serum levels of lactic dehydrogenase, hyperproteinorachia, and affectation of deep cerebral structures like periventricular regions, basal ganglia, brain stem, and cerebellum [28].

Differential diagnosis must be made with multiform glioblastoma, primary neuroectodermic tumor, metastases of anaplastic carcinoma and melanoma. Immunohis- 
tochemistry with the follow monoclonal antibodies: cytokeratin, HMB 45, acid glial glycoprotein, epithelial membrane antigen and CD 99 are highly valuables for the correct classification of this type of neoplasia [1].

Regarding treatment, a better survival has been shown with the combination of two treatments (methotrexate and radiotherapy) at not too high doses to avoid or reduce the neurological sequelae of these treatments [29].

In conclusion, we present the clinicopathological characteristics of four cases of DBCL in the CNS, three of them classified as originating from activated lymphocyte B, and the other from the germinal center (GC) with aberrant expression of CD3 (pan-T marker).

\section{REFERENCES}

[1] A. C. Feller and J. Diebold, "Histopathology of Nodal and Extranodal Non-Hodgkin's Lymphomas. Based on the WHO Classification,” 3rd Completely Revised and Updated Edition, Springer-Verlag, Berlin, Heidelberg, New York, 2004, pp. 330-334.

[2] S. Swerdlow, E. Campo, L. N. Harris, S. E. Jaffe, A. S. Pileri, H. Stein, et al., "WHO Classification of Tumours of Haematopoietic and Lymphoid Tissues," 4th Edition, International Agency for Research of Cancer, Lyon, 2008, pp. 240-241.

[3] T. Batchelor and J. S. Loeffler, "Primary CNS Lymphoma,” Journal of Clinical Oncology, Vol. 24, No. 8, 2006, pp. 1281-1288. doi:10.1200/JCO.2005.04.8819

[4] L. Jiang, A. L. Marlow, J. S. Cooper, V. Ch. Roemeling, M. D. Menke, A. J. Copland, et al., "Selective Central Nervous System Tropism of Primary Central Nervous System Lymphoma,” International Journal of Clinical and Experimental Pathology, Vol. 3, No. 8, 2010, pp. 763-767.

[5] M. Montesinos-Rongen, S. Reiner and D. Marina, "Primary Lumphoma of the Central Nervous System: Just DLBCL or Not?” Blood, Vol. 113, No. 1, 2009, pp. 7-10. doi:10.1182/blood-2008-04-149005

[6] F. H. Hochberg and D. C. Miller, "Primary Central Nervous System Lymphoma,” Journal of Neurosurgery, Vol. 68, 1998, pp. 835-853. doi:10.3171/jns.1988.68.6.0835

[7] T. M. Alécio, J. M. Alécio, P. H. Aguilar and R. Ramina, "Primary Central Nervous System Lymphomas in Immunocompetents Patients,” Neurocirugia, Vol. 17, 2006, pp. 46-53.

[8] M. Schabet, "Epidemiology of Primary CNS Lymphoma," Journal of Neuro-Oncology, Vol. 43, No. 3, 1999, pp. 199-201. doi:10.1023/A:1006290032052

[9] B. Bataille, V. Delwail, E. Menet, P. V. Marcq, P. Ingrand, M. Wager, et al., "Primary Intracerebral Malignant Lymphoma. Report of 248 Cases,” Journal of NeuroOncology, Vol. 92, No. 2, 2000, pp. 261-266.

[10] W. Kuker, T. Nagele, A. Korfel, S. Hecky, E. Thiel, M. Bamberg, et al., "Primary Central Nervous System Lymphomas (PCNSL) MRI Features at Presentation in 100
Patients,” Journal of Neuro-Oncology, Vol. 72, No. 2, 2005, pp. 169-177. doi:10.1007/s11060-004-3390-7

[11] A. Coulon, F. Lafitte, K. Hoang-Xuan, N. Martin-Duverneuil, K. Mokhtari, J. Blustajn, et al., "Radio-Graphic Findings in 37 Patients of Primary CNS Lymphoma in Immunocompetent Patients,” European Radiology, Vol. 12, 2002, pp. 329-340. doi:10.1007/s003300101037

[12] N. Erdag, R. M. Bhorade, R. A. Alberico, N. Yousuf and M. R. Patel, "Primary Lymphoma of the Central Nervous System: Typical and Atypical CT and MR Imaging Appearances,” American Journal of Roentgenology, Vol. 176, No. 5, 2001, pp. 1319-1326.

[13] G. Guinto, I. Felix, N. Arechiga, V. Arteaga and K. Kovacs, "PCNSL in Immunocompetent Patients," Histology and Histopathology, Vol. 19, 2004, pp. 963-972.

[14] K. M. Braaten, R. A. Betensky, L. de Leval, Y. Okada, F. H. Hochberg, D. N. Lous, et al., "BCL-6 Expression Predicts Improved Survival in Patients with Primary Central Nervous System Lymphoma,” Clinical Cancer Research, Vol. 9, No. 3, 2003, pp. 1063-1069.

[15] S. Camilleri-Broet, E. Criniere, P. Broet, V. Delwail, K. Mokhtari, A. Moreau, et al., "A Uniform Activated B-Cell-Like Immunophenotype Might Explain the Poor Prognosis of Primary Central Nervous System Lymphomas Analysis of 83 Cases,” Blood, Vol. 107, No. 1, 2006, pp. 190-196. doi:10.1182/blood-2005-03-1024

[16] C. H. Lin, K. T. Kuo, S. S. Chuang, S. H. Kuo, J. H. Chang, K. C. Chang, et al., "Comparison of the Expression and Prognostic Significance of Differential Markers between Diffuse Large B-Cell Lymphoma of Central Nervous System Origin and Peripheral Nodal Origin," Clinical Cancer Research, Vol. 12, 2006, pp. 1152-1156. doi:10.1158/1078-0432.CCR-05-1699

[17] K. M. Algino, R. W. Thomason, D. E. King, M. M. Montiel and F. E. Craig, "CD 20 (Pan-B Cell Antigen) Expression on Bone Marrow Derived T Cells,” American Journal of Clinical Pathology, Vol. 106, No. 1, 1996, pp. 76-81.

[18] S. J. Hamilton-Dutoit, G. Pallesen, "B Cell Associated Monoclonal Antibody L 26 May Occasionally Label T Cell Lymphomas,” APMIS, Vol. 97, No. 11, 1989, pp. 1033-1036. doi:10.1111/j.1699-0463.1989.tb00514.X

[19] J. Linder, L. Y. Ye, D. S. Harrington, J. O. Armitage, D. D. Weissenburger, "Monoclonal Antibodies Marking BCell Non Hodgkin's Lymphoma in Paraffin Embedded Tissues,” Modern Pathology, Vol. 1, No. 1, 1988, pp. 2934.

[20] D. A. Arber and L. M. Weiss, “CD 43: A Review," Applied Immunohistochemistry, Vol. 1, 1993, pp. 88-96.

[21] D. A. Arber and L. M. Weiss, “CD 5: A Review," Applied Immunohistochemistry, Vol. 3, 1995, pp. 1-22.

[22] H. S. Khalidi, R. K. Brynes, P. Borwne, C. H. Koo, H. Battifora and L. J. Medeiros, "Intravascular Large B-Cell Lymphoma: The CD 5 Antigen Is Expressed by a Subset of Cases,” Modern Pathology, Vol. 11, No. 10, 1998, pp. 983-988.

[23] P. J. Kurtin, K. S. Hobday, S. Ziesmer and B. L. Caron, 
"Demonstration of Distinct Antigen Profiles of Small B-Cell Lymphomas by Paraffin Section Immunohistochemistry," American Journal of Clinical Pathology, Vol. 112, No. 3, 1999, pp. 319-329.

[24] T. Inaba, C. Shimazaki, T. Sumikuma, A. Okano, M. Hatsuse and A. Okamoto, "T-Cell Associated AntigenPositive B-Cell Lymphoma," Leukemia \& Lymphoma, Vol. 42, No. 6, 2001, pp. 1161-1171. doi:10.3109/10428190109097741

[25] A. Matolcsy, A. Chadburn and D. M. Knowles, "De Novo CD 5 Positive and Richter's Syndrome-Associated Diffuse Large B Cell Lymphomas Are Genotypically Distinct," American Journal of Pathology, Vol. 147, No. 1, 1995, pp. 207-216.

[26] J. Wang, Ch. Chen, S. Lau, R. I. Raghavan, E. H. Rowsell, J. Said, et al., "CD-3 Positive Large B-Cell Lymphoma," American Journal of Surgical Pathology, Vol. 33, No. 4, 2009, pp. 505-512. doi:10.1097/PAS.0b013e318185d231

\section{Abbreviations}

DLBCLCNS = Diffuse Large B Cell Lymphoma of the Central Nervous System.

$\mathrm{HIV}=$ Human Immunodeficiency Virus

CNS $=$ Central Nervous System

DLBCL = Diffuse Large B-Cell Lymphoma

$\mathrm{CB}=$ Centroblastic

LMP-1 = Latent Membrane Protein of the Epstein-Barr Virus
[27] N. Vajpayee, J. Hussain, I. Tolocica, R. E. Hutchison and A. Gajra, "Expression of Signal Transducter and Activator of Transcription 3 (STAT 3) in Primary Central Nervous System Diffuse Large B-Cell Lymphoma: A Retrospective Analysis of 17 Cases," Journal of NeuroOncology, Vol. 100, No. 2, 2010, pp. 294-253. doi:10.1007/s11060-010-0188-7

[28] A. J. Ferreri, J. Y. Blay, M. Reni, F. Pasini, M. Spina, A. Ambrosetti, et al., "Pronostic Scoring System for Primary CNS Lymphomas: The International Extra-Nodal Study Group Experience,” Journal of Clinical Oncology, Vol. 21, No. 2, 2003, pp. 266-272. doi:10.1200/JCO.2003.09.139

[29] R. Yamanaka, K. Morii, Y. Shinbo, J. Homma, M. Sano, N. Tsuchiya, et al., "Results of Treatment of 112 Cases of Primary CNS Lymphoma,” Japanese Journal of Clinical Oncology, Vol. 38, No. 5, 2008, pp. 373-380. doi:10.1093/jico/hyn027

MRI = Magnetic Resonance Imagen

CAT $=$ Computarizade Axial Tomography

$\mathrm{M}=$ Male

$\mathrm{F}=$ Female

DLBCL = Diffuse Large B-Cell Lymphoma.

$\mathrm{ABL}=$ Activated B Lymphocyte DLBCL

$\mathrm{GC}=$ Diffuse Large B. Cell Lymphoma Originated in the Germinal Center by Immunophenotype 